\title{
Teoría de la pena
}

\section{Theory of punishment}

Cesar Augusto Ávila Aparicio

Doctorado en Derecho Procesal Penal

Universidad de San Carlos de Guatemala

liccesaravila@hotmail.com

Recibido: 27/06/2021

Aceptado: 15/08/2021

\section{Referencia del artículo}

Ávila Aparicio, C. A. (2021). Teoría de la pena. Revista Diversidad Científica, 1(1). 71-84.

\section{Resumen}

\section{DOI: https://doi.org/10.36314/diversidad.v1i1.9}

El trabajo desarrollado, se basa en realizar un análisis de los fines de la pena en base a las teorías que buscan establecer su justificación, se parte por explicar el concepto de la misma, su naturaleza jurídica la cual tiene íntima relación con el principio de legalidad contenido en los artículos 17 de la Constitución Política de la República de Guatemala vigente, para explicar por último la actitud adoptada en la legislación guatemalteca. Dicho sistema jurídico cree en la rehabilitación de los reclusos y en teoría el sistema penitenciario debería estar adecuado para ese fin, preparado e instalado con programas reales de rehabilitación, sostenibles, funcionales y reales, donde se pueda palpar un cambio de actitud y aptitud.

Palabras clave: pena, fines, rehabilitación, reinserción Social 


\begin{abstract}
The work developed is based on carrying out an analysis of the purposes of the penalty based on the theories that seek to establish its justification, it starts by explaining the concept of it, its legal nature which is closely related to the principle of legality contained in articles 17 of the Political Constitution of the Republic of Guatemala in force, to finally explain the attitude adopted in Guatemalan legislation. This legal system believes in the rehabilitation of inmates and in theory the prison system should be adequate for that purpose, prepared and installed with real, sustainable, functional and real rehabilitation programs, where a change in attitude and aptitude can be felt.
\end{abstract}

Keywords: penalty, ends, rehabilitation, Social reintegration 


\section{Introducción}

El Estado tiene por mandato Constitucional el deber de garantizar a sus habitantes una vida en armonía y paz social, bajo esa premisa surge la necesidad de crear un sistema y/o normativa que establezca cuáles son las conductas prohibidas para la sociedad y las consecuencias para su realización, es así como surge el Derecho penal regulando este en su contenido los delitos, faltas, penas y medidas de seguridad.

La pena tiene su origen en el momento mismo que surge el derecho penal, es decir adquirió su naturaleza juntamente con la rama antes mencionada pues es parte de ella, al considerar el delito una infracción a la ley pues la pena es una sanción derivada de esa infracción cometida, consecuencia jurídica de la realización de una conducta prohibida penalmente.

Es preciso tener claro que independientemente se considere a la pena un castigo su finalidad será la rehabilitación del delincuente, razón por la cual el considerar que con penas más severas se evitara que la sociedad siga sufriendo de hechos delictivos es una utopía que existirá únicamente en el pensamiento de una sociedad cansada del fenómeno criminal, por lo que atendiendo al fin del sistema penitenciario es ésta la herramienta que debería de utilizar el Estado para lograr que los reclusos puedan reincorporarse a la sociedad como personas de bien, esto sin dejar por un lado que también debe de acudirse a la prevención del delito a través de mejorar las condiciones de vida de la población en general, velando no solo por brindarle una protección preferente a grupos vulnerables, también implementando programas que permitan un avance de la persona humana en general y que los abismos entre la pobreza, pobreza extrema y población con condiciones económicas estables se reduzca y con ello lograr que la niñez y adolescencia puedan ser objeto de utilización en grupos criminales, que mantengan en un clima de miedo, inseguridad y zozobra constante a la sociedad.

Aspectos que fueron tomados en cuenta para la elaboración del presente ensayo denominado "Teoría de la pena", el cual tiene por objeto analizar las teorías que explican la justificación de la pena y establecer la aptitud que adopta el sistema jurídico guatemalteco. 


\title{
Contenido
}

\section{Concepto de pena}

Es preciso que se conozca los orígenes de la pena, toda vez que la misma es una consecuencia jurídica por la realización de una conducta prohibida por la ley.

Moritz (1928) indica que

\begin{abstract}
"El hombre primitivo consideraba todo aquello que sobrepasa su limitadísimo conocimiento, casi siempre, producto de una forma incipiente de observación y que alteraba su vida normal como fruto de influencias malignas, sobrenaturales, emanadas de seres fantásticos habitualmente antropoásticos que solo podrían ser comprendidos mediante la magia. Entre estos fenómenos se alinean la lluvia, el rayo, el trueno, acontecimientos para los cuales no tenían explicaciones y que irían a ejercer, dentro de la visualización de esos pueblos primitivos, directa influencia sobre la vida de cada uno y de toda la comunidad generando premios o castigos en razón del comportamiento exteriorizado. Esos seres sobrenaturales vivían en las piedras, en los ríos, en los animales. Frente al resultante premio-castigo, se tornaba imperioso adecuar la conducta humana a la finalidad de obtener la benevolencia o la protección de esos seres imaginarios (pág. 160).
\end{abstract}

Con este criterio, Pessagno y Bernardi (1953) explican de manera bastante lógica la existencia del tótem, a lo cual expresan:

que era un animal, una fuerza sobrenatural (o una planta, pero preferentemente un animal) al cual se consideraba vinculado, de modo particular, con los individuos integrantes de una tribu, una familia, una casta o un sector de la comunidad, que podrían, o no, ser transmitidos hereditariamente una vez individualizados; esto porque, al lado de el tótem individual, existían los de grupo, de miembros de la comunidad o clan, y se establecía entre ellos una jerarquía y graduación(pág. 10).

Pimentel (1992), con referencia al origen de la pena, considera por tanto, “...que las primeras prohibiciones y los primeros castigos o penas se han encontrado en las relaciones totémicas pues es tenida como indubitable la conclusión de que el totemismo fortaleció los lazos integradores de la comunidad..." (pág. 18). Passagno (1953), por su parte realiza el siguiente aporte: "que no pocas instituciones deben reconocer como surgidas de su seno; así, por ejemplo, la exogamia, y no menos verdadero será que, gracias a sus prohibiciones y tabú, la vida humana comenzó a encauzarse en base a principios de orden y de pacífica convivencia impuestos por el temor al castigo o sanción" (pág. 13). 
Zaffaroni (1981), escribe:

....si bien no puede hablarse de una continuidad histórica, puede reconocerse en la ley penal una lucha de la que va surgiendo, arduamente, una concepción del hombre como persona, es decir como un ser dotado de autonomía ética.

Este concepto no surge de una sola vez, ni tampoco en una forma progresiva, sino que se gesta de una sucesión de marchas y contramarchas, cuyo origen se pierde en el terreno de la antropología cultural y cuyo desarrollo -y alternativamente- continúa hasta nuestros días, no sin dejar de estar amenazado el futuro(pág. 318).

En ese sentido se procede a definir la pena, como la limitación de derechos que es impuesta por el Estado a través de los órganos jurisdiccionales competentes como consecuencia de la realización de una comisión delictiva. Como se ha visto, la pena es un tema que es tratado por diferentes profesionales, quienes dan sus diferentes puntos de vista con el fin de dar un explicación satisfactoria para entender cuál es su significado.

Emile Durkheim citada por Garland (1999), define a la pena de la siguiente manera:

Es la representación directa del orden moral de la sociedad y un ejemplo de como este orden se representa y sostiene; en ese sentido, sostiene que la pena es la reacción de los mismos de una sociedad impulsada por sentimientos irracionales y emotivos, frente a una transgresión contra el orden moral, que pretende restaurarlo. (pág. 42)

Por su parte Reyes (1996) la considera: "Como la supresión o coartación de un derecho personal que el Estado impone por medio de su rama jurisdiccional a sujeto imputable que ha sido declarado responsable de un hecho punible" (pág. 245). Osorio (2001), es del criterio que "la pena es un castigo impuesto por autoridad legítima, especialmente de índole judicial, a quien ha cometido un delito o falta” (pág. 733).

Se debe tener presente que para la sociedad al momento que existe una comisión delictiva, la pena viene a constituir un mecanismo para combatir el delito, su esperanza está en ver al delincuente privado de su libertad y que este cumpla muchos años en esa situación, para que entienda que su actuar no fue el adecuado, la población en general tiene la creencia que la única sanción que debería emitir el Estado es restringir su derecho a una vida libre, olvidando que existen diferentes formas de sanciones, las cuales se analizaran en su momento. 
Lo anterior denota que para la sociedad guatemalteca, incluso para los mismos operadores judiciales, el tener personas privadas de libertad es sinónimo de justicia, pero del análisis del artículo 19 de la Constitución Política de la República de Guatemala, la pena es considerada como la herramienta por medio de la cual se pretende lograr la readaptación social y la reeducación de los reclusos. Puede ser defina como la privación o restricción de un derecho, ordenado por un órgano jurisdiccional en sentencia, mediante la cual el Estado busca la rehabilitación de la persona que ha cometido un delito.

El paradigma de definir la pena como una infracción a la ley penal debe ir cambiando, porque si bien es cierto la misma es una consecuencia jurídica derivada de la realización de una conducta prohibida penalmente, no quiere decir que necesariamente considerar que el privar de su libertad a una persona es sinónimo de disminución de la delincuencia, es por ello la importancia de aportar definiciones sobre lo que es una pena y con ello lograr una mejor comprensión, teniendo claro que para Guatemala lo que se pretende es lograr con ella la rehabilitación de las personas que han cometido un delito a través de la ejecución y cumplimiento de una pena, permitirle que se logre encausar a la sociedad como una persona de bien.

\section{Naturaleza de la pena}

La pena tiene su origen en el momento mismo que surge el derecho penal, es decir adquirió su naturaleza juntamente con la rama antes mencionada pues es parte de ella, al considerar el delito una infracción a la ley pues la pena es una sanción derivada de esa infracción cometida, consecuencia jurídica de la realización de una conducta prohibida penalmente. Por lo que la misma es de naturaleza pública pues la potestad exclusiva de determinar cuáles son las conductas prohibidas penalmente entiéndase delitos y faltas, así como sus consecuencias jurídicas, le compete únicamente al Estado. De Mata Vela (2000) aporta:

Partiendo del Jus Puniendi como el derecho que corresponde única y exclusivamente al Estado de castigar, concepción que ha sido universalmente aceptada en el Derecho penal moderno. Es pues la pena de naturaleza pública porque solo él Estado puede crearla, imponerla y ejecutarla; a ningún particular le está permitido juzgar criminales y atentar contra ellos imponiendo una pena (pág. 269).

Su naturaleza jurídica tiene íntima relación con el principio de legalidad contenido en los artículos 17 de la Constitución Política de la República de Guatemala vigente, el cual preceptúa "No hay delito ni pena sin ley anterior. No son punibles las 
acciones $u$ omisiones que no estén calificadas como delito o falta y penadas por ley anterior a su perpetración..." $1^{\circ}$ del Código Penal, Decreto 17-73 del Congreso de la República de Guatemala, determina "De la legalidad. Nadie podrá ser penado por hechos que no estén expresamente calificados como delitos o faltas, por ley anterior a su perpetración; ni se impondrán otras penas que no sean las previamente establecidas en la ley".

En ese sentido, el principio de legalidad viene a limitar el poder punitivo del Estado, pues claramente le impone que los delitos, faltas, penas y medidas de seguridad deben ser creadas por la ley y estar contenidas en la misma, esto quiere decir que la función creadora le corresponde al Organismo legislativo y las funciones de aplicación y ejecución al Organismo Judicial. La Corte de Constitucionalidad en relación al citado principio, en el expediente 3753-2012, sentencia de fecha seis de marzo del año dos mil trece, gaceta número 107, señala:

\begin{abstract}
Este principio, que a su vez constituye una garantía para un juzgamiento conforme al principio jurídico del debido proceso constituye uno de los elementos centrales de la persecución penal en una sociedad democrática, e impone la obligación al legislador ordinario de definir en la forma más clara precisa posible (lex certa) cuáles son esas acciones u omisiones que son consideradas punibles mediante la determinación de tipos penales que contemplan una clara definición de la conducta incriminada, concretizar sus elementos y permitir así deslindar conductas punibles de aquellas que no lo son...
\end{abstract}

De lo anteriormente citado, se puede colegir que la ley penal se integra de dos aspectos que son la conducta prohibida penalmente es decir el tipo penal y consecuencia jurídica que es la pena, cuando el sistema de justicia se enfrenta a la oportunidad de imponer una sanción penal a quien ha transgredido una norma lesionando un bien jurídico tutelado, también se encuentra a la dificultad que representa su creación y justificación, por lo cual como ya se hizo mención solo le compete al Estado determinarlas, teniendo en cuenta que debe cumplirse no solo con la sanción, sino también con la protección y rehabilitación, velando por el cumplimiento de lo que para el efecto regulan los artículos $1^{\circ}$ y $2^{\circ}$ de la Constitución Política de la República de Guatemala relativos al bien común y a sus deberes.

Al establecer que la pena es de naturaleza pública, es preciso abordar cuáles son sus fines, esto porque la creación de la pena y la razón de su finalidad son competencias que el Estado debe justificar e individualizar, para que se aplique a un sujeto acusado de haber lesionado un bien jurídico o inobservado la vigilancia de la norma, según la posición dogmática que se asuma. El determinar una pena es una de las labores más complejas para todos los operados de justicia, pues consiste en el 
proceso que se transforma una pena imponible de acuerdo a lo establecido en un determinado tipo del Código Penal, de allí la importancia que el Estado a través del Organismo Legislativo sea claro al momento de establecer por medio de una ley los tipos penales que tienden a regular las conductas prohibidas y sus respectivas consecuencias.

\section{Fines de la pena y las teorías de su justificación}

Para poder establecer los fines de la pena, debemos acudir a las diferentes teorías que existen en relación a la misma, logrando con ello poder determinar desde el punto de vista del sistema normativo cuál de ellas aplica en Guatemala, lo anterior resulta relevante, para dejar a un lado el paradigma que solo a través de la prisión se logra disminuir los altos índices delincuenciales que afronta la sociedad bajo la errónea creencia que la pena solo debe ser considerada como un castigo, es preciso crear nuevos paradigmas que permitan dar cumplimiento a lo consagrado en el artículo 19 de la Constitución Política de la República de Guatemala relativo a la rehabilitación del recluso.

\subsection{Teorías Absolutas}

Bustos (1994), explica:“También conocida como "Teorías absolutas, retribucioncitas o retributivas, se basa en la creencia de que la culpabilidad del autor debe compensarse mediante la imposición de una sanción, con el objeto de alcanzar la justicia. A través de ella se considera que la pena debe imponerse solo porque se ha delinquido" (pág. 115).

Sanz (2000), al respecto señala:

Las teorías retributivas deben su contenido a la tradición filosófica del idealismo y del cristianismo. La justificación de la pena está en la justicia misma y esta se atribuye por la culpabilidad del autor; solo esta última justifica la imposición del mal precisamente por el mismo mal que ha significado el delito(pág. 29).

En esta teoría solo se explica el fundamento de la pena, el por qué se castiga, pero no se aclara el contenido de sus fines. Claus Roxin (1976), considera: "la culpabilidad del autor sea compensada mediante la imposición de un mal penal. La pena, pues, no sirve para nada, sino que lleva su fin en sí misma. Tiene que ser, porque 
tiene que imperar la justicia"(pág. 12). Considerar hoy en día la pena como una retribución es quedarnos cortos pues no solo es considerarla como un castigo frente al delincuente.

Rodríguez (2019), en relación a las teorías absolutas que explican el fin de la pena, expone:

La opción de punitur quia peccatum est, se ha equiparado con las denominadas teorías absolutas de la penal, que encuentran la bondad de esta institución en sí misma y no en sus consecuencias ( $y$, en esa medida se separan de las teorías relativas, que destacan la capacidad de la pena para alcanzar determinadas finalidades en una cantidad suficiente). Su idea de base es bastante sencilla, para los autores que defienden esta postura imponer un mal a quien ha realizado otro mal con anterioridad es algo justo, siendo esto suficiente para soportar la estructura penal (aunque de la amenaza e imposición de la pena no se obtengan otros fines adicionales). (pág. 223)

La sociedad cansada del fenómeno delictivo ve en la pena un castigo por medio del cual busca que el penado deje de delinquir y que entre más grave sea esa sanción mayor justicia habrá, concepto erróneo que incluso hoy en día hay jueces que basados en ese criterio lo único que han logrado es que exista sobrepoblación en los centros penales, con la agravante que al carecer de un programa rehabilitador se continúe con actividades ilícitas dentro de los mismos, razón por la cual dicha teoría fue descartada por el sistema jurídico guatemalteco.

\subsection{Teorías relativas}

Como contraparte a las teorías absolutistas, surgen las teorías relativas de la pena, estas se justifican por su orientación hacia fines enfocados en la prevención de hechos delictivos, pues estas se basan en lograr disuadir a la población en general que debido a la gravedad de las sanciones que tienen los tipos penales no delincan, así como también hacerle ver a quien ya fue condenado por el cometimiento de un hecho delictivo este no vuela a sus actividades criminales, de allí que estas teorías se fundamentan en dos aspectos: La prevención especial y la general.

\subsubsection{Teoría de la prevención especial}

En relación a la presente teoría, debe tomarse en cuenta que la pena no es solo sancionar, también busca que a través de su cumplimiento, el penado entienda que 
su actuar no fue el adecuado y que si en caso vuelve a delinquir las consecuencias se esos actos serán nefastos, puesto que aparte de ser sancionado nuevamente, automáticamente se le limita en sus derechos para optar a algún beneficio.

De Mata refiere:

Nace con el positivismo italiano y luego se desarrolla en Alemania por Franz Von Liszt, la pena consiste para esta teoría en una intimidación individual que recae únicamente sobre el delincuente con el objeto de que no vuelva a delinquir; no pretende como lo anterior retribuir el pasado, sino prevenir la comisión de nuevos delitos, corrigiendo al corregible, intimidando al intimidado o haciéndolo inofensivo al privarlo de la libertad al que no es corregible ni intimidable. (pág. 271)

Esta teoría pretende establecer que la pena tiene como fin prevenir que la persona que ha sido condenada por un delito no vuelva a delinquir, es decir que a raíz de la sanción que fue cumplida éste entendió que su actuar debe ser apegado a la ley y que si no cambia el mismo continuando con sus actividades delictivas las consecuencias jurídicas de sus conductas prohibidas penalmente serán mayores.

\subsubsection{Teoría de la prevención general}

La pena se valora en cuanto va dirigida a los miembros de la sociedad que pretende regular, para que en el futuro ante la amenaza de ello se abstengan de realizar conductas prohibidas penalmente. De Matacitando a Puig, en referencia a la presente teoría expone:

La base criminal es un fenómeno común a todas las personas; es decir, que la tendencia a realizar actos criminales no se circunscribe, en el sentido de la teoría lombrosiana del delincuente nato, a una determinada especie humana sino que como criminalidad latente instintiva existe en todos los hombres, incluso en los mejores. Ahora bien, con el fin de contrarrestar y oponerse a los efectos de esta inclinación se hace necesaria la institución de determinados impulsos, sin los que no podrá llevarse a cabo la vida común social.(pág. 272)

A través de esta teoría se pretende que la sociedad misma entienda que las penas no solo fueron creadas para castigar al delincuente, también para comprender que al momento de decidir realizar una conducta prohibida esto traerá como consecuencia su juzgamiento y por ende si es probada su responsabilidad penal una sanción. 


\section{Guatemala y el fin de la pena}

La teoría que adopta Guatemala en cuanto a la finalidad de la pena es la rehabilitación, pues considera que la misma no solo debe castigar y proteger, también debe de buscarse herramientas que permitan la reinserción social del penado, el artículo 19 de la Constitución Política de la República de Guatemala, señala: "Sistema penitenciario. El sistema penitenciario debe tender a la readaptación social y la reeducación de los reclusos y cumplir en el tratamiento de los mismos, con las siguientes normas mínimas..."

La Corte de Constitucionalidad en relación al citado principio, en el expediente 19122004, sentencia de fecha veintisiete de abril del año dos mil cinco, gaceta número 76, señala:

El artículo 19 de la Constitución Política de la República preconiza la existencia de un sistema penitenciario, en el que fundamentalmente se observen que los reclusos deben ser tratados como seres humanos, prohibiéndose así la realización de toda conducta que atente contra su dignidad. En ese orden de ideas, y ateniendo al carácter finalista del texto supremo, es inaceptable que a un recluso no se le considere como alguien susceptible de ejercer derechos y asumir obligaciones.

El sistema jurídico guatemalteco cree en la rehabilitación de los reclusos y en teoría el sistema penitenciario debería estar adecuado para ese fin, preparado e instalado con programas reales de rehabilitación, sostenibles, funcionales y reales, donde se pueda palpar un cambio de actitud y aptitud luego de someterse a los mismos, aunque en la actualidad es otra la realidad que se vive en virtud que no existen políticas claras que velen por cumplir con el mandato constitucional al extremo de caer en una situación insostenible pues el hacinamiento, la sobrepoblación y la falta de recursos han convertido los centros penales en escuelas del crimen, donde los reclusos en vez de salir rehabilitados, egresan especializados en la forma de como cometer delitos.

\section{Conclusión}

Para la sociedad guatemalteca incluso para los mismos operadores judiciales, el tener gente privada de libertad es sinónimo de justicia. Del análisis del artículo 19 de la Constitución Política de la República de Guatemala, la pena es considerada como la herramienta por medio de la cual se pretende lograr la readaptación social y a la reeducación de los reclusos. Por lo que puede ser definida como la privación o restricción de un derecho, ordenado por un órgano jurisdiccional en sentencia, 
mediante la cual el Estado busca la rehabilitación de la persona que ha cometido un delito.

El paradigma de definir la pena como una infracción a la ley penal debe ir cambiando, esto porque si bien es cierto la misma es una consecuencia jurídica derivada de la realización de una conducta prohibida penalmente, no quiere decir que necesariamente considerar que el privar de su libertad a una persona es sinónimo de disminución de la delincuencia, es por ello la importancia de aportar definiciones sobre lo que es una pena y con ello lograr una mejor compresión, teniendo claro que para Guatemala lo que se pretende es lograr con ella la rehabilitación de las personas que han cometido un delito a través de la ejecución y cumplimiento de una pena, permitirle que se lograre encausar a la sociedad como una persona de bien.

El Estado constitucional de derecho redefine el concepto de la pena en el derecho penal, ya que al valorar los bienes jurídicos tutélados como la vida, seguridad y bien común, debe desempeñar una función de prevención general, donde todos los ciudadanospuedan ser protegidos de la intimidación o amenazas de posibles delincuentes.

Entonces al hablar de la pena necesariamente debemos hablar de la función preventiva, con arreglo a los principios de exclusiva protección de bienes jurídicos, los valores axiologicos que deben de protegerse, estos van cambiando como todo en una era globalizada y de constante cambio, así también cambian los fines de las penas trasladándose a los intereses en juego de las diferentes sociedades.

\section{Declaración}

El estudio se realizó de acuerdo al Código de Ética y Buenas Prácticas COPE.

\section{Conflicto de intereses}

El autor declara no tener ningún conflicto de intereses. 


\section{Referencias}

Bustos, J. (1994). Bases críticas de un nuevo derecho penal. Santiago deChile: Editorial Jurídica Conosur.

De Mata Vela, J. F. (2000). Derecho penal guatemalteco. Guatemala: Editorial Llerena.

Pessagno R. y P. J. Bernardi, H. (1953). Temas de historia penal. Buenos Aires, Argentina: Editorial Perrot.

Garland, D. (1999). Castigo y sociedad. México: Editorial Siglo Veintiuno Editores.

Hoernes, M. (1928). Prehistoria. Barcelona, España: Editorial labor.

Ossorio, M. (2001). Diccionario de ciencias jurídicas, políticas y sociales. Argentina: Editorial Heliasta.

Pimentel, P. (1992). El crimen y la pena en la actualidad. Sao Pablo, Brasil: Editorial RT.

Reyes, A. (1996). Derecho penal. Bogota: Editorial Temis.

Rodríguez H. D. (16 de abril de 2019). Teoría de la Pena. Revista en Cultura de la legalidad(Número 16), 219-232.

Roxin, C. (1976). Problemas básicos del derecho penal. Madrid: Editorial Reus.

Sanz, N. (2000). Derecho penal. Madrid: Editorial Colex.

Zaffaroni, E. R. (1981). Tratado de Derecho Penal, Parte General, tomo III. Buenos Aires: Ediar. 


\section{Sobre el autor \\ Cesar Augusto Ávila Aparicio}

Abogado y Notario, con grado académico de Licenciado en Ciencias Jurídicas y Sociales, egresado de la Universidad de San Carlos de Guatemala, con estudios de postgrados de Maestría de Derecho Procesal Penal en la Facultad de Ciencias Jurídicas y Sociales del Centro Universitario de Oriente -CUNORI-, Magistrado presidente de la Sala Mixta de la Corte de Apelaciones del Departamento de Chiquimula.

\section{Copyright (c) Cesar Augusto Ávila Aparicio}

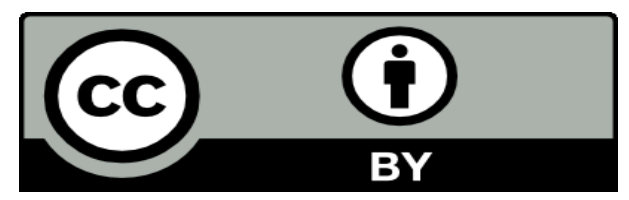

Este texto está protegido por una licencia CreativeCommons 4.0.

Usted es libre para compartir, copiar y redistribuir el material en cualquier medio o formato y adaptar el documento, remezclar, transformar y crear a partir del material para cualquier propósito, incluso comercialmente, siempre que cumpla la condición de atribución: usted debe reconocer el crédito de una obra de manera adecuada, proporcionar un enlace a la licencia, e indicar si se han realizado cambios. Puede hacerlo en cualquier forma razonable, pero no de forma tal que sugiera que tiene el apoyo del licenciante o lo recibe por el uso que hace. 